\section{Genotype and Parental Combination Influence Efficiency of Cybrid Induction in Citrus by Electrofusion}

\author{
Takaya Moriguchi, Tetsushi Hidaka ${ }^{1}$, and Mitsuo Omura \\ Fruit Tree Research Station, Okitsu Branch, Shimizu, Shizuoka 424-02, Japan
}

Toshiaki Motomura ${ }^{2}$ and Tomoya Akihama

Faculty of Agriculture, Meiji University, Tama, Kawasaki, Kanagawa 214, Japan

Additional index words. protoplast fusion, rDNA, mtDNA, cpDNA, Citrus breeding

Abstract. Interspecific hybridizations by electrofusion of embryogenic callus cells from 'Seminole' tangelo (Citrus reticulata Blanco x C. paradisi Macf.), 'Hazzara (Abohar)', or 'Ohta' ponkan ( $C$. reticulata Blanco) and leaf cells from 'Lisbon' lemon [C. limon (L.) Burm.f.] or rough lemon $(C$.jambhili Lush.), respectively, were performed. Electrofusion of 'Seminole' tangelo and 'Lisbon' lemon, 'Hazzara (Abohar)' and rough lemon, and 'Ohta' ponkan and rough lemon resulted in 33, 43, and 36 plants, respectively. Seven to 10 plants in each combination were selected randomly and used to investigate nuclear and cytoplasmic genomes. Regenerated plants derived from electrofusion of 'Seminole' tangelo and 'Lisbon' lemon, and 'Hazzara (Abohar)' and rough lemon possessed the same restriction fragment pattern for nuclear rDNA as that of the mesophyll parents and the same mitochondrial DNA (mtDNA) restriction pattern as that of the respective suspension parents, indicating that they were cybrids. In contrast, all the plants resulting from a combination between 'Ohta' ponkan and rough lemon were confirmed by nuclear rDNA and mtDNA analysis to be somatic hybrids. The analysis of chromosome number supported the results of Southern blot hybridization. The results suggest that specific cell lines, parental combinations, or both can increase the efficiency of inducing cybrids in Citrus by electrofusion.

Mitochondrial and chloroplast genomes encode genes related to male sterility and photosynthesis (Leaver and Gray, 1982; Whitfeld and Bottomley, 1983). Therefore, Citrus cybrids have become useful tools for the analysis of these important traits. However, information regarding cytoplasmic inheritance in Citrus is limited. Vardi et al. (1987) first succeeded in producing Citrus cybrids using a donor-recipient protoplast fusion system, in which nucellar callus protoplasts from either parent were treated with gamma rays and iodoacetate. Saito et al. (1993) and Yamamoto and Kobayashi (1995) reported producing cybrids without using mutagenic inactivation (i.e., standard symmetric fusion procedure). Producing cybrids by symmetric fusion has been reported for crosses between sudachi (C. sudachi hort. ex Shirai) and lime (C. aurantifolia Swing.) or lemon (Saito et al., 1993), between navel orange [C. sinensis (L.) Osb.] and grapefruit (C. paradisi Macf.) (Saito

Received for publication 18 July 1995 . Accepted for publication 2 Jan. 1996. Contribution no. B-218 of the Fruit Tree Research Station. The cost of publishing this paper was defrayed in part by the payment of page charges. Under postal regulations, this paper therefore must be hereby marked advertisement solely to indicate this fact.

${ }^{1}$ Current address: Japan International Research Center for Agricultural Science, Okinawa Branch, Ishigaki, Okinawa 907, Japan.

${ }^{2}$ Current address: Shoda Syoyu Co., Tatebayashi, Gunma 374, Japan.

HortS Cience, Vol. 31(2), ApriL 1996 used for obtaining protoplasts according to Hidaka and Omura (1992).

Protoplasts of leaf mesophyll were obtained from fully expanded upper leaves of 'Lisbon' lemon and rough lemon plants grown in a greenhouse at 25 to $35 \mathrm{C}$ according to Hidaka and Omura (1992).

Protoplasts isolated from suspension cultures and leaves were fused electrically according to Hidaka and Omura (1992) and Hidaka et al. (1995). The mixtures subsequently were cultured according to Hidaka and Omura (1992) and were subjected to selection using a medium containing $0.15 \mathrm{M}$ sucrose and $0.45 \mathrm{~m}$ glucose (Motomura et al., 1995). The embryoids then were transplanted onto a $0.2 \%$ Gelrite (Kelco, Merck \& Co. Rahway, N.J.)-solidified MS medium containing $0.1 \mathrm{~m}$ galactose, $0.1 \mathrm{~m}$ sorbitol, and 1 $\mu \mathrm{M}$ gibberellic acid $\left(\mathrm{GA}_{3}\right)$. Regenerated shoots were transplanted into rooting medium $(0.2 \%$ Gelrite-solidified MS medium containing 0.1 M galactose, $0.1 \mathrm{~m}$ sorbitol, $10 \mathrm{nM} \mathrm{GA}_{3}$, and 100 nm naphthaleneacetic acid). Sometimes, shoots were grafted directly onto rootstocks of 'Troyer' citrange $[C$. sinensis (L.) Osb. $\mathrm{x}$ Poncirus trifoliata (L.) Raf.].

Shoot tips pretreated at $4 \mathrm{C}$ for $16 \mathrm{~h}$ were fixed with 3 methanol : 1 acetic acid (v/v) and

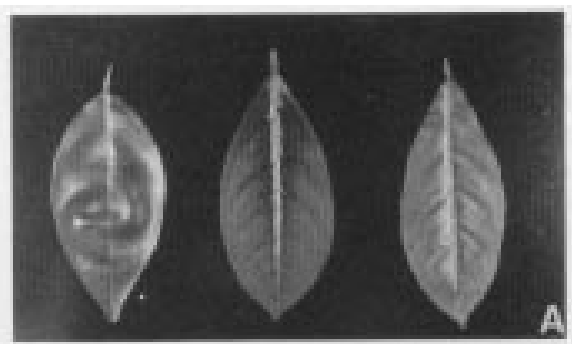

et al., 1993), and between satsuma mandarin (C. unshiu Marc.) and sweet orange [C. sinensis (L.) Osb.] (Yamamoto and Kobayashi, 1995). These cybrids possessed rDNA restriction fragments similar to those of the mesophyll parent, whereas mitochondrial DNA (mtDNA) restriction fragment patterns were identical to those of the nucellar callus parent. However, the frequency of inducing cybrids was not always high. Therefore, the development of more efficient methods for inducing cybrids is essential for introgressing maternally inherited cytoplasmic characters. In our study, we report a high frequency of Citrus cybrid induction between 'Seminole' tangelo and 'Lisbon' lemon, and 'Hazzara (Abohar)' and rough lemon by symmetric electrofusion.

\section{Materials and Methods}

Nucellar-derived embryogenic calli of 'Seminole' tangelo, 'Hazzara (Abohar)', or 'Ohta' ponkan were maintained on solidified Murashige and Skoog (1962) medium (MS) containing $0.2 \mathrm{M}$ sucrose and $50 \mu \mathrm{M}$ kinetin. Before isolation of protoplasts, callus cultures were transferred to a liquid MS medium containing the same components and were subcultured at least three times at 2-week intervals between each transfer. The suspension cultures then were kept on a hormone-free liquid MS medium containing $0.1 \mathrm{~m}$ galactose and $0.1 \mathrm{M}$ sorbitol for 1 to 2 weeks. They were subcultured up to three times in the same medium at 2 -week intervals. These calli were
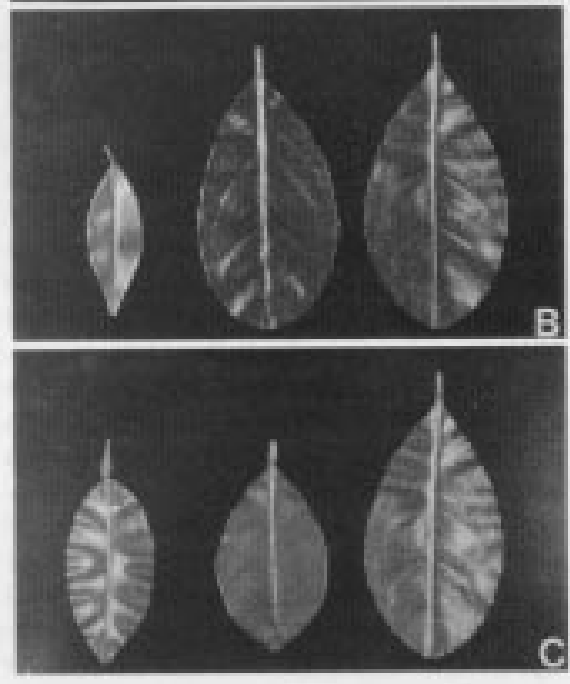

Fig. 1. Leaf morphology of cybrids and somatic hybrids. (A) Combination between 'Seminole' tangelo (suspension parent) and 'Lisbon' lemon (mesophyll parent); (left to right) 'Seminole' tangelo, cybrid, and 'Lisbon' lemon. (B) Combination between 'Hazzara (Abohar)' (suspension parent) and rough lemon (mesophyll parent); (left to right) 'Hazzara (Abohar)', cybrid, and rough lemon. (C) Combination between 'Ohta' ponkan (suspension parent) and rough lemon (mesophyll parent); (left to right) 'Ohta' ponkan, somatic hybrid, and rough lemon. 
were macerated enzymatically according to Ito et al. (1992). Chromosomes in the macerated cells were stained with 4',6-diamidino-2phenyl-indole (DAPI) and were observed under an epifluorescence microscope at $\times 1000$ magnification.

Total DNA was extracted by the sodium dodecylsulfate method (Dellaporta et al., 1983) from the calli of 'Seminole' tangelo, 'Hazzara (Abohar)', 'Ohta' ponkan, the leaves of 'Lisbon' lemon and rough lemon, and the regenerated plants. DNA $(5 \mu \mathrm{g})$ was digested with the endonucleases BamHI, DraI, or EcoRI. Digests then were electrophoresed in $0.8 \%$ agarose gels and were transferred to a nylon membrane (Hybond- $\mathrm{N}^{+}$, Amersham, U.K.) with $0.4 \mathrm{~m} \mathrm{NaOH}$ solution. The blots were probed with Digoxigenin (DIG)-labeled 7.7 kilobasepair (kbp) EcoRI fragment obtained from rice rDNA (Takaiwa et al., 1984) for confirmation of hybridity. For mtDNA analysis, the coxI (1.5 kbp) restriction fragment obtained from sugar beet (Beta vulgaris L.) and $\operatorname{atpA}(1.4 \mathrm{kbp})$ and the $r r n 26(4.4 \mathrm{kbp})$ restriction fragments obtained from pea (Pisum sativum L.) (provided by T. Mikami, Hokkaido Univ., Sapporo, Hokkaido, Japan) were used as probes. For chloroplast DNA (cpDNA) analysis, pTBa3 derived from $\mathrm{BamHI}$ restriction fragments of Nicotiana tabacum L. was used as a probe (Sugiura et al., 1986). Labeling and hybridization were performed according to protocol for the detection of DIG-labeled nucleic acid with 3-(2'-Spiroadamantane)-4methoxy-4-(3"'-phosphoryloxy)-phenyl-1,2dioxetane (AMPPD) (Boehringer Mannheim, Mannheim, Germany).

\section{Results}

Following the electrofusion, 33 plants from the combination between 'Seminole' tangelo and 'Lisbon' lemon, 43 plants from 'Hazzara (Abohar)' and rough lemon, and 36 plants from 'Ohta' ponkan and rough lemon were obtained after acclimatization.

The leaf morphology of the plants from the combinations between 'Seminole' tangelo and 'Lisbon' lemon, and 'Hazzara (Abohar)' and rough lemon was similar to that of the respective mesophyll parent (Fig. 1 A and B). In contrast, all the plants from the electrofusion of 'Ohta' ponkan and rough lemon showed an intermediate leaf morphology (Fig. 1C). Sixteen plants selected from the combination of 'Seminole' tangelo and 'Lisbon' lemon and 17 plants from the 'Hazzara (Abohar)' and rough lemon electrofusion combination were diploid $(2 n=18)$ (Fig. 2 A and B). Sixteen selected plants derived from the combination of 'Ohta' ponkan and rough lemon were amphidiploid $(2 n=18+18=36)$ (Fig. 2C).

Among selected plants, seven to 10 in each electrofusion combination were reselected to investigate the nuclear and cytoplasmic genomes. Restriction fragment length polymorphism patterns probed with rDNA indicated that the regenerated plants from the 'Ohta' ponkan and rough lemon combination were somatic hybrids (Fig. 3C). However, the plants from the electrofusion of 'Seminole' tangelo and 'Lisbon' lemon (Fig. 3A) and of 'Hazzara (Abohar)' and rough lemon (Fig. 3B) were not somatic hybrids because they exhibited the same rDNA banding patterns observed in respective parental leaves.

The analysis with coxI probe showed that all the regenerated plants had the same mtDNA banding pattern as those of the suspension parents (Fig. 4A-C). Similar results were obtained using $r r n 26$ for investigating relationships of regenerated plants resulting from 'Seminole' tangelo and 'Lisbon' lemon electrofusion and with atpA used to examine regenerants between 'Hazzara (Abohar)' and rough lemon and regenerants between 'Ohta' ponkan and rough lemon (data not shown).

Using pTBa3 as a probe, we found that regenerants from the electrofusion of 'Hazzara (Abohar)' or 'Ohta' ponkan and rough lemon possessed the same cpDNA restriction fragment patterns as those of the suspension parents [i.e., 'Hazzara (Abohar)' and 'Ohta' ponkan] (Fig. $5 \mathrm{~A}$ and B). Analysis of the cpDNA in the plants regenerated from the combination of 'Seminole' tangelo and 'Lisbon' lemon revealed no unique parentspecific bands. These results indicated that regenerants from 'Seminole' tangelo and 'Lisbon' lemon and from 'Hazzara (Abohar)'
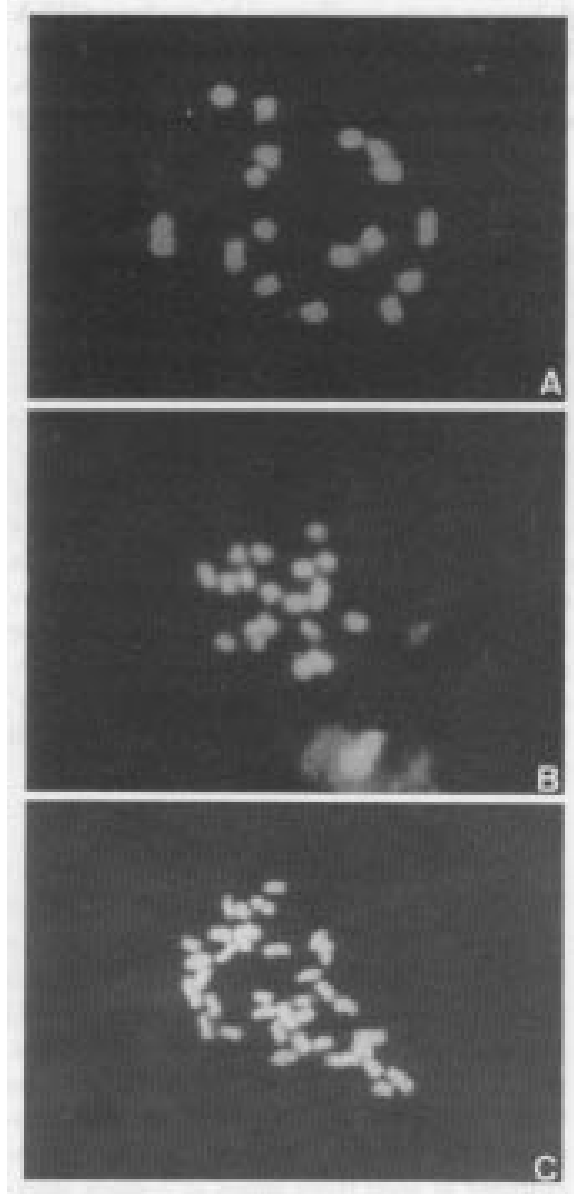

Fig. 2. Chromosome number of cybrid between (A) 'Seminole' tangelo and 'Lisbon' lemon $(2 n=$ 18), cybrid between (B) 'Hazzara (Abohar)' and rough lemon $(2 n=18)$, and $(\mathbf{C})$ somatic hybrid between 'Ohta' ponkan and rough lemon $(2 n=$ 36). and rough lemon electrofusion combination were cybrids.

\section{Discussion}

There are reports of embryoids forming from unfused embryogenic callus and mesophyll protoplasts (Kobayashi et al., 1988; Tusa et al., 1990); however, in our study, the selection medium with high concentrations of sugars $(0.15 \mathrm{M}$ sucrose and $0.45 \mathrm{M}$ glucose $)$ (Motomura et al., 1995) allowed only heterokaryons to form embryoids because unfused mesophyll protoplasts could not divide and the suspension protoplasts could not form embryoids. Regenerated plants from the electrofusion combination of 'Seminole' tangelo and 'Lisbon' lemon and between 'Hazzara (Abohar)' and rough lemon possessed patterns of rDNA and cytoplasmic DNA identical to those of leaf and suspension parents, respectively, indicating that they were not escapes, but cybrids. In these electrofusion combinations, using embryogenic callus cells of 'Seminole' tangelo and 'Hazzara (Abohar)' manda-

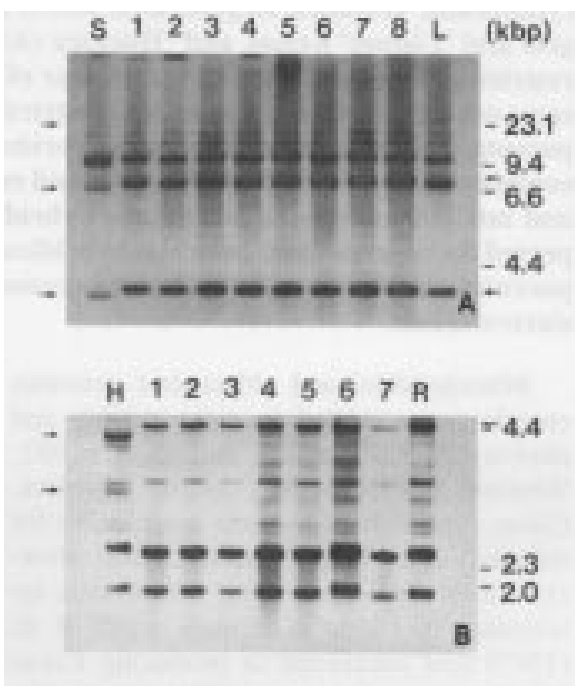

$\begin{array}{lllllllllll}1 & 2 & 3 & 4 & 5 & 6 & 7 & 8 & 9 & 10 & \mathrm{~A}\end{array}$

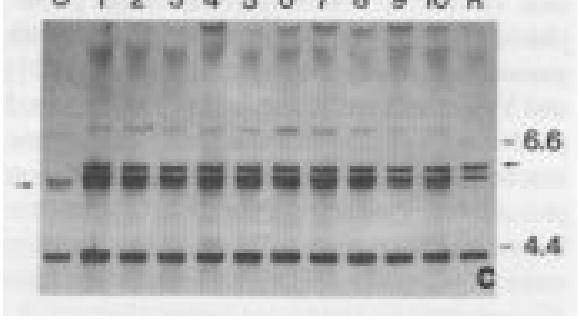

Fig. 3. Southern blot hybridization of total DNA to rice-rDNA probe. (A) Combination between 'Seminole' tangelo (suspension parent) and 'Lisbon' lemon (mesophyll parent) (DraI digestion); lane $\mathrm{S}=$ 'Seminole' tangelo, 1 to $8=$ cybrids, and L $=$ 'Lisbon' lemon. (B) Combination between 'Hazzara (Abohar)' (suspension parent) and rough lemon (mesophyll parent) (BamHI digestion); lane $\mathrm{H}=$ 'Hazzara (Abohar)', 1 to 7 = cybrids, and $\mathrm{R}=$ rough lemon. $(\mathbf{C})$ Combination between 'Ohta' ponkan (suspension parent) and rough lemon (mesophyll parent) (EcoRI digestion); lane $\mathrm{O}=$ 'Ohta' ponkan, 1 to $10=$ somatic hybrids, and $\mathrm{R}=$ rough lemon . Arrows indicate the bands specific to both parents.

HortScience, Vol. 31(2), April 1996 
rin allowed successful cybrid induction (100\%), while 'Ohta' ponkan produced only somatic hybrids when electrofused with rough lemon.

Eventually, the chromosomes of one parent are eliminated following symmetric fusions, especially between more distantly related species (Kao, 1977; Kumar and Cocking, 1987). However, in Citrus, chromosomes have been spontaneously eliminated following symmetric fusion only in cross-compatible, interspecific, fusion combinations, as shown in our study and elsewhere (Saito et al., 1993; Yamamoto and Kobayashi, 1995). In these cases, only the suspension parent nuclear genomes were eliminated.

In our previous studies, only amphidiploids were produced by electrofusion of 'Seminole' tangelo and Indian atalantia (Atalantia monophylla DC.) or Chinese box-orange [Severiniabuxifolia (Poir.) Tenore] (Motomura et al., 1995) and of 'Hazzara (Abohar)' and Microcitrus australis (Planch.) Swing. (Motomura et al., unpublished data), where, despite using 'Seminole' tangelo and 'Hazzara

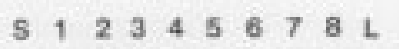

(kbp)

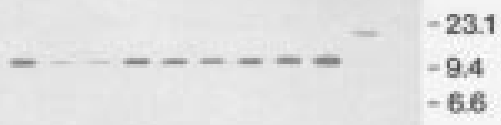

A

$\begin{array}{lllllllll}\mathrm{H} & 1 & 2 & 3 & 4 & 5 & 6 & 7 & \mathrm{~A}\end{array}$

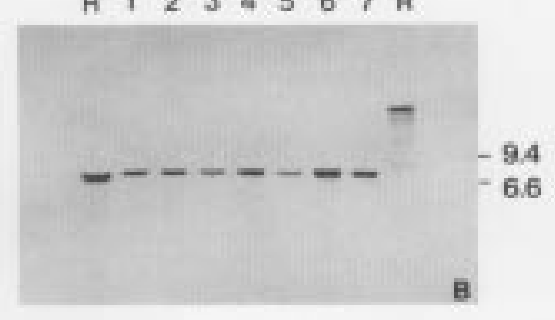

$\begin{array}{llllllllllll}0 & 1 & 2 & 3 & 4 & 5 & 6 & 7 & \mathrm{~B} & 9 & 10 & \mathrm{R}\end{array}$

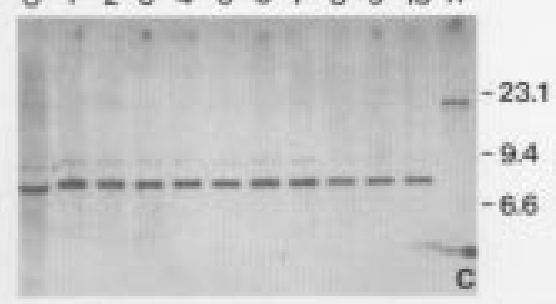

F1g. 4. Southern blot hybridization of total UNA to the mtDNA coxI probe. (A) Combination between 'Seminole' tangelo (suspension parent) and 'Lisbon' lemon (mesophyll parent) (DraI digestion); lane $\mathrm{S}=$ 'Seminole' tangelo, 1 to $8=$ cybrids, and L = 'Lisbon' lemon. (B) Combination between 'Hazzara (Abohar)' (suspension parent) and rough lemon (mesophyll parent) (DraI digestion); lane $\mathrm{H}=$ 'Hazzara (Abohar)', 1 to $7=$ cybrids, and $\mathrm{R}=$ rough lemon. $(\mathbf{C})$ Combination between 'Ohta' ponkan (suspension parent) and rough lemon (mesophyll parent) (DraI digestion); lane $\mathrm{O}=$ 'Ohta' ponkan, to $10=$ somatic hybrids, and $\mathrm{R}=$ rough lemon
(Abohar)' as suspension parents, no cybrids could be obtained. Furthermore, cybrids were not obtained in the electrofusion among interspecific combinations of satsuma mandarin and yuzu (C. junos Sieb. ex Tan.) (Hidaka and Omura, 1992). These results suggest that it is easier to induce cybrids among interspecific combinations than among intergeneric ones and also that selection of the mesophyll cell parent as well as callus suspension parent is important for inducing interspecific cybrids. Saito et al. (1993) reported that the percentage of cybrid induction was $25 \%$ in regenerated clones from the electrofusion sudachi and lime and $80 \%$ from fusion of sudachi and lemon. Furthermore, Yamamoto and Kobayashi (1995) obtained only one cybrid following a fusion of satsuma mandarin and sweet orange. The percentage of cybrid induction could be increased by using appropriate parental combinations of callus and mesophyll parents in the standard symmetric fusion procedures in Citrus.

Vardi (1981) reported that the sugar combinations of the culture medium affected the plating efficiency of protoplasts. Suitable sugar type and its combinations for colony formation were different depending on the Citrus genotypes. Protoplasts of 'Ponkan' were sensitive to sorbitol, resulting in a decrease of plating efficiency (Vardi, 1981). In our study, cybrids were obtained from two fusion combinations ['Seminole' (+) Lisbon lemon and 'Hazzara (Abohar)' (+) rough lemon], while only somatic hybrids were formed between 'Ohta' ponkan and rough lemon. Sugar components may be important for inducting hybrids and cybrids as well as for selecting cell lines or parental combinations for electrofusion.

In our study, regenerated somatic hybrids and cybrids showed unilateral transmission, with a preference for the chloroplast and mitochondrial genomes derived from the suspension parent. Saito et al. (1993) suggested that the mitochondria of the suspension parent might play an important role in Citrus embryogenesis because they observed that the regenerated somatic hybrids and cybrids had identical mtDNA restriction fragments with those of the suspension parent. However, in addition to the complete transmission of cytoplasmic genome from the suspension parent, Motomura et al. (1995) obtained recombination of mtDNA in somatic hybrids between the Citrus suspension parent and Atalantia or Severinia mesophyll parents, suggesting that the complete mtDNA from the suspension parent may not always be necessary for embryogenesis.

Because molecular studies are easier to perform in materials with a lower ploidy level, difficulties may arise when analyzing mtDNA in tetraploid somatic hybrids. Thus, the high efficiency of cybrids induction carrying recombinant mtDNA might contribute to elucidate the mitochondrial role of the suspension parent on Citrus embryogenesis. Furthermore, new combinations of cytoplasmic genome could contribute useful material for Citrus breeding programs.

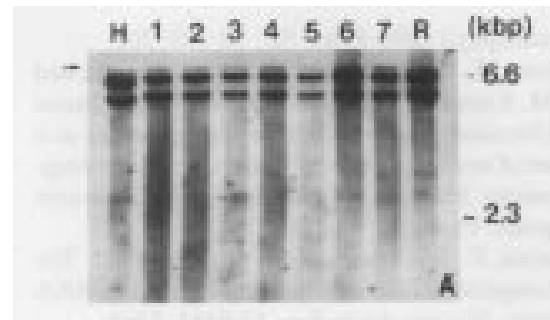

$012345678910 \mathrm{R}$

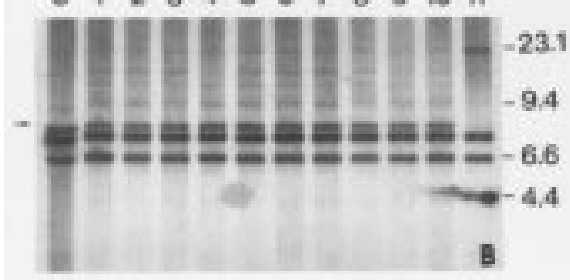

Fig. 5. Southern blot hybridization of total DNA to the cpDNA pTBa3 probe. (A) Combination between 'Hazzara (Abohar)' (suspension parent) and rough lemon (mesophyll parent) (DraI digestion); lane $\mathrm{H}=$ 'Hazzara (Abohar)', 1 to $7=$ cybrids, and $\mathrm{R}=$ rough lemon. (B) Combination between 'Ohta' ponkan (suspension parent) and rough lemon (mesophyll parent) (DraI digestion); lane $\mathrm{O}=$ 'Ohta' ponkan, 1 to $10=$ somatic hybrids, and $\mathrm{R}=$ rough lemon. Arrows indicate the bands specific to suspension parents.

\section{Literature Cited}

Dellaporta, S.L., J. Wood, and J.B. Hicks. 1983. A plant DNA minipreparation: Version II. Plant Mol. Biol. Rpt. 1:19-21.

Hidaka, T., T. Moriguchi, T. Motomura, S. Katagi, and M. Omura. 1995. Development of a new electrode chamber and its efficiency in protoplast fusion in Citrus. Breeding Sci. 45:237-239.

Hidaka, T. and M. Omura. 1992. Regeneration of somatic hybrid plants obtained by electrical fusion between satsuma mandarin (Citrusunshiu) and rough lemon (C. jambhiri) or yuzu $(C$. junos). Jpn. J. Breeding 42:79-89.

Ito, Y., M. Omura, H. Nesumi, and T. Yoshida. 1992. Improvement of reparation and observation methods for Citrus chromosomes. Bul. Fruit Tree Res. Sta. (Minist. Agr. Forest. Fish., Japan) 23:57-66.

Kao, K.K. 1977. Chromosomal behavior in somatic hybrids of soybean-Nicotiana glauca. Mol.Gen. Genet. 150:225-230.

Kobayashi, S., T. Ohgawara, E. Ohgawara, I. Oiyama, and S. Ishi. 1988. A somatic hybrid plant obtained navel orange (Citrus sinensis) and satsuma mandarin (C. unshiu). Plant Cell, Tissue Organ Cult. 14:63-69.

Kumar, A. and E.C. Cocking. 1987. Protoplast fusion: A novel approach to organelle genetics in higher plants. Amer. J. Bot. 74:1289-1303.

Leaver, C.J. and M.W. Gray. 1982. Mitochondrial genome organization and expression in higher plants. Annu. Rev. Plant Physiol. 33:373-402.

Motomura, T., T.Hidaka, T.Moriguchi, T. Akihama, and M. Omura. 1995. Intergeneric somatic hybrids between Citrus and Atalantia or Severinia by electrofusion, and recombination of mitochondrial genomes. Breeding Sci. 45:309-314.

Murashige, T. and F. Skoog. 1962. A revised medium for rapid growth and bioassays with tobacco tissue cultures. Physiol. Plant. 15:473497.

Saito, W., T. Ohgawara, J. Shimizu, S. Ishii, and S. Kobayashi. 1993. Citrus cybrid regeneration following cell fusion between nucellar cells and 


\section{Breeding, Cultivars, Rootstocks, \& Germplasm Resources}

mesophyll cells. Plant. Sci. 88:195-201.

Sugiura, M., K. Shinozaki, N. Zaita, M. Kusuda, and M. Kumano. 1986. Clone bank of the tobacco (Nicotiana tabacum) chloroplast genomes as a set of overlapping restriction endonuclease fragments: Mapping of eleven ribosomal protein genes. Plant Sci. 44:211-216.

Takaiwa, F., K. Oono, and M. Sugiura. 1984. The complete nucleotide sequence of a rice $17 \mathrm{~s}$ rRNA gene. Nucleic Acids Res. 12:5441-5444.
Tusa, N., J.W. Grosser, and F.G. Gmitter, Jr. 1990. Plant regeneration of 'Valencia' sweet orange, 'Femminello' lemon, and the interspecific somatic hybrid following protoplast fusion. J. Amer. Soc. Hort. Sci. 115:1043-1046.

Vardi, A. 1981. Protoplast derived plants from different Citrus species and cultivars. Proc. Intl. Soc. Citricult. 1:149-152.

Vardi, A., A. Breiman, and E. Galun. 1987. Citrus cybrids: Production by donor-recipient proto- plast-fusion and verification by mitochondrialDNA restriction profiles. Theor. Appl. Genet. 75:51-58.

Whitfeld, P.R. and W. Bottomley. 1983. Organization and structure of chloroplast genes. Annu. Rev. Plant Physiol. 34:279-310.

Yamamoto, M. and S. Kobayashi. 1995. A cybrid plant produced by electrofusion between Citrus unshiu (satsuma mandarin) and C. sinensis (sweet orange). Plant Tissue Cult. Lett. 12:131-137. 